UDC 615.851.3-053.9

\title{
ELDERLY'S MEANINGFUL OCCUPATION AS A REHABILITATION MEAN IN OCCUPATIONAL THERAPY
}

\author{
AUTHOR'S DATA: \\ Aida Kalashyan, OT MA \\ The republican psychological-pedagogical support center \\ Occupational Therapist \\ Contacts: aidakalashyan@gmail.com
}

\begin{abstract}
The aim of the study is to find out the importance of occupation in the lives of elderly people and identify the occupation therapy effect of their well-being.

The survey was conducted on quantitative and qualitative research for the collection of research data. For quantitative research was used a testing method with the use of Chris Mayer's and Interests questionnaires. Qualitative research is based on quantitative research results, accordingly has been designed a questionnaire that has helped to reveal the research question. MS Excel program was applied for analyzing quantitative research, and thematic analysis method for qualitative research.

The results of the research reveal that most elderly people do not have meaningful occupation, do not do any kind of job, do not engage in their preferred occupation. These circumstances are interpreted as the work for the livelihoods organized by the institution. In addition, this was explained not only by the lack of alternative occupation options in the institution, but also by the lack of desire of the elderly. The elderly voiced also financial and health problems that hindered their involvement in their preferred occupation.
\end{abstract}

Key words: Elderly, occupation, occupational therapy, favorite occupation, aging process, elderly institutional life.

\section{INTRODUCTION}

Aging is one of the most important stages of life that a person must live as efficiently as possible (Bonder \& Goodman, 2008). The concept of effective aging implies that when a person maintains the normal course of his life in the physical, mental and social aspects, reduces the negative aging process (Johnson \& Walker, 2016). 
Currently, many specialists regularly update their theoretical and practical knowledge to determine the phenomena of aging and the problem of aging (Johnson \& Walker, 2016). Such specialists include occupational therapists who, since 1940, have been involved in individual interventions with elderly who have various illnesses or limitations in their daily life (WFOT, 2009).

Occupational therapy is client-centered profession which provides health care and wellbeing of the individuals by the way of meaningful occupation (AOTA, 2019; WFOT, 2009). Occupations are central to a client's (person's, group's, or population's) identity and sense of competence and have particular meaning and value to that client. The occupation in occupational science literature has different definitions (AOTA, 2014). The occupation is goal-directed pursuits that typically extend over time, have meaning to the performance, and involve multiple tasks (Christiansen, Baum \& Bass-Haugen, 2005).

\section{LITERATURE REVIEW}

Aging can be defined as age irreversible changes during the development of the organism, which limit the person's adaptive capabilities (AOTA, 2014), for that reason, as Bonder and Goodman mention in their scientific article aging is one of the most important stages of life that a person must live as efficiently as possible (Bonder \& Goodman, 2008). According to Khrisanova's article the concept of effective aging implies that when a person maintains the normal course of his life in the physical, mental and social aspects, reduces the negative aging process (Johnson \& Walker, 2016).

Currently, many specialists regularly update their theoretical and practical knowledge to determine the phenomena of aging and the problem of aging (Johnson \& Walker, 2016). Such specialists include occupational therapists. Occupational therapy is client-centered profession which provides health care and well-being of the individuals by the way of meaningful occupation (AOTA, 2019; WFOT, 2009), and the occupation, according to the Johnson, enhance the quality of life of elderly (Johnson \& Walker, 2016). The research of Christiansen, Baum, Bass-Haugen which deals with performance, participation, and well-being has shown that many elderlies have reached retirement age lose their basic occupation, in fact, most of their daily lives become "empty" and should be made more saturated (Christiansen, Baum \& Bass-Haugen, 2005), because, according to Johnson, an important aspect of the quality of life in elderly is achieving maximum independence in their daily life (Johnson \& Walker, 2016). 
Johnson also mentioned that often on independence of daily life of elderly can have a great influence, such as psychological and social health (Johnson \& Walker, 2016), which plays an important role in the ability to adapt to different life situations (Cumming, Thomas, Szonyi, Salkeld, et al., 1999). And based on these conditions, by regularly perform therapeutic intervention occupational therapists help the elderly to do what they want and what they need. In addition, occupational therapy helps elderly to live in a full life, improve their health, prevent and overcome injuries, disorders, and in some cases also acquire the most comfortable life skills with them (Hansen, Ashby \& Baug, 2015).

Thus, as Kiernan and Winkleby noted in their work, the occupational therapist should give importance to their participation in various activities, which allows the elderly to include in some occupation (Chevannes, 2002).

The occupation in occupational science literature has different definitions (AOTA, 2014). According to the research of Christiansen, Baum, Bass-Haugen the occupation is goal-directed pursuits that typically extend over time, have meaning to the performance, and involve multiple tasks (Christiansen, Baum \& Bass-Haugen, 2005).

Within the framework of the "Occupation in lifestyle redesign: the Well Elderly Study Occupational Therapy Program" research of Jackson, Carlson, Mandel, Zemke, Clark in 1998 reveals the effectiveness of occupational therapy in the lives of elderly (Cumming, Thomas, Szonyi, Salkeld, et al., 1999; WHO, 2010; Enderby \& Wade, 2001). The interventions were based on theoretical and practical knowledge of occupational therapy science which highlight the change in quality of life enabling participants to individually choose the occupation, which will provide their well-being (Enderby \& Wade, 2001).

The above mentioned framework proved the role of occupational therapeutic interventions, because occupations have a cumulative effect on our health, they may determine whether we can live independently in older age or need someone's care (WHO, 2010).

Within the other framework of the "Occupation: purposefulness and meaningfulness as therapeutic mechanism" research by Trombly in 1995 tried to find out how does purposefulness and meaningfulness of daily life can effect on person's life quality (Trombly, 1995).

The result of the research has shown that the meaningfulness and the purposefulness of daily performance leads to intellectual and physical well-being and the occupational therapeutic interventions not only ensure the final result, but also the high indicator of the future quality of person's life (Trombly, 1995). 
Besides showing maximum independence in their daily life and participating in some occupations, in the high quality of life of elderly Haak highlights the environment (Khristanfova, 1999). Achieving maximum independence in their daily life and their participation in environmental events should also assist the state (RA Government 18.09.2014 N 39 Protocol Decision). According to the 2014 data, currently there are 8 state and non-state boarding-houses in the Republic of Armenia. In the boarding-houses elderly are provided with all essential items and services necessary for a livelihood: (including shelter, furniture, clothing, personal hygiene items, foodstuff, first medical aid, leisure activities) (RA Government 18.09.2014 N 39 Protocol Decision).

Harutyunyan in his scientific article highlights the current location of elderly and favorable environmental conditions (Harutyunyan, 2012), but living in boarding-houses, in the nursing homes considerably limited the independence and the choice of occupation of elderly that have a significant impact on the well-being and quality of their life (Harutyunyan, 2012).

In addition, involvement in some occupation balances life and the person feels satisfaction from life as Brown and Franklin mentioned. Life satisfaction predicts a person's psychological well-being (Wade, 2003), and this provides development of interpersonal relationships and communication skills (Chudnova, 2015; Wade, 2003).

Taking into consideration this fact, a research has been carried out the aim of which is to find out the importance of occupation in the lives of elderly people and identify the occupation therapy effect of their well-being.

Therefore, in this context, the problem of research was formulated as follows: "What kind of rehabilitation effect will meaningful occupation provide on elderly' welfare".

\section{METHODOLOGY}

The survey was conducted on quantitative and qualitative research for the collection of research data. For quantitative research was used a testing method (Wade, 2003). Testing is one of the most common method of sociology. With these method quantitative and qualitative indicators can be obtained, which are contributing to the discovery of a research problem. There are specified standardized and projective testing methods. The standardized tests were used as a data collection method during the quantitative research, because by using them can be determined quantitative estimates. For revealing the problem of occupation of elderly were selected Chris Mayer's and Interests questionnaires (Kielhofner, 2002; Mayers, 1998), which are standardized tests. Chris 
Mayer's and Interests questionnaires are client-centered approaches and in occupational therapy they are used before intervention. The questionnaires are including almost all the areas of occupation and reveal the needs of elderly. However, during the research have been selected and have been taken into consideration those areas of occupation which have a close relationship with the problem of occupation, as a result, from the questionnaires have been removed those areas which do not relate to the occupation (Mayers, 1998).

The Interests questionnaire was used so that we could include the broader areas of occupations and identify the frequency of the occupations. In addition, the Interests questionnaire determines the types preferred occupations of client's, whether the client wants to continue or carry out this occupation (Kielhofner, 2002). Based on the analysis of the results of the Chris Mayer's and Interests questionnaires during the research have been created a new questionnaire, which would explain the problem of the research. Created questionnaire include questions that are aimed to reveal the cultural events that occur inside the institution, for what reason the elderly cannot participate in these events, and what events they would like to participate in. As the elderly gave extensive answers during the data collection created questionnaire provides quantitative estimates. According to the given answers, especially were highlighted those answers that were closely related to the research problem during the data analysis.

\section{Participants}

For studying the research question in 2018 from April to September was conducted a research with 15 elderlies in "Narek" NGO. The survey was conducted with 14 (93\%) of the elderly, and from 1 person (7\%) received a rejection. The $71 \%$ of the responders are female, while the $29 \%$ are male. Three of the participants have disabilities, nine of them need care and two are refugees (Table 1).

Table 1. Demographic data of participants.

\begin{tabular}{|r|r|r|r|}
\hline $\mathbf{N}$ & Sex & Age & Status \\
\hline $\mathbf{1}$ & Female & 77 & Need care \\
\hline $\mathbf{2}$ & Female & 71 & Need care \\
\hline $\mathbf{3}$ & Female & 78 & Need care \\
\hline $\mathbf{4}$ & Female & 68 & Refugee \\
\hline $\mathbf{5}$ & Female & 80 & Need care \\
\hline
\end{tabular}




\begin{tabular}{|r|r|r|r|}
\hline $\mathbf{6}$ & Female & 93 & Need care \\
\hline $\mathbf{7}$ & Female & 84 & Refugee \\
\hline $\mathbf{8}$ & Female & 62 & Has disability \\
\hline $\mathbf{9}$ & Female & 68 & Need care \\
\hline $\mathbf{1 0}$ & Female & 72 & Need care \\
\hline $\mathbf{1 1}$ & Male & 64 & Need care \\
\hline $\mathbf{1 2}$ & Male & 67 & Has disability \\
\hline $\mathbf{1 3}$ & Male & 70 & Need care \\
\hline $\mathbf{1 4}$ & Male & 63 & Has disability \\
\hline
\end{tabular}

\section{Ethical considerations}

Taking into account the fact that currently there was no research ethics committee in Republic of Armenia, gaining official ethical license for the research, so, firstly, the plan of the master's thesis was discussed with the supervisor. Secondly, it was confirmed in the session of the Chair of speech and rehabilitation therapy. Before starting the field works, permission was gained from the director of the nursing home. Further, participants were given the written information on the research aim, their rights and ethical obligations of the researcher. All participants, as well as the director of the institution, have given their written agreement by signing the information paper. The researcher gave confidence to participants that their private issues were preserved and confidentiality was assured. After all these processes have been implemented, the main works have started.

\section{Data collection}

Data was collected by using standardized questionnaires, in which 14 respondents gave short answers. This gave an opportunity to discover the frequency of occupation in the lives of elderly and their desire to engage in occupation. In addition, the standardized testing allows us to save time and not get bored. The questions were asked directly by the researcher in a separate room, located inside the institution.

The questions in the questionnaire were aimed to reveal the preferred occupation of elderly, including those in which they want to participate. Also, by using these questions we can identify those obstacles because of what the elderly is not engaged in these occupations (Kielhofner, 2002; 
Mayers, 1998). This type of data collection provides quantitative indicators during the data analysis.

Based on the standardized questionnaires during the data collection, was designed a questionnaire, which provides qualitative indicators during the data analysis. Created questionnaire include questions that are aimed to reveal the cultural events that occur inside the institution, for what reason the elderly cannot participate in these events, and what events they would like to participate in. As the elderly gave extensive answers during the data collection created questionnaire provides quantitative estimates. According to the given answers, especially were highlighted those answers that were closely related to the research problem during the data analysis.

\section{Data analysis}

According to the World Health Organization (WHO), people over 60 years old are considered elderly (AOTA, 2019; Searle, Mahon, Iso-Ahola, Sdrolias et al., 1998), but, since the retirement age of the Republic of Armenia (RA) is 63 years, so the participants are older than 63 years (AOTA, 2019).

MS Excel program was applied for analyzing quantitative research (Braun \& Clarke, 2006; Johnson \& Walker, 2016), what allows to analyze the primary data more quickly, also it is accessible almost for everyone.

The data analysis process took place in 5 sequential stages, by which we obtained a percentage response, further it was expressed through graphic images.

At the first stage of the process, were selected and grouped the equivalent answers (for example, "yes", "no", "free", "hard", "sometimes", "rarely"). Then, according to their amount, they were turned into digital units and got the corresponding names.

At the second stage the database was created. It was realized through the establishment of appropriate columns. Columns were matched in nominal units (for example, "communication", "work / education", "favorite occupation") and the number of responders who had been coded and numbered $(1,2,3,4$, etc.). At the third stage, data was imported. At the fourth stage the primary data was analyzed. As a result, we got the percentage correlation. At the fifth stage the data was expressed through graphic images (Figure 1, 2, 3, 4, 5) (Brown \& Frankel, 1993; Graff, VernooijDassen, Thijssen, Dekker et al., 2006). 
Qualitative data analysis was performed by using Brown and Clark's thematic analysis method, which helps you search, analyze, and identify data (Mishra, 2003). The analysis is done by identifying, reading and repeating the topics ( $\mathrm{Ng}$, Lo, Lee, Lam et al., 2006). The applicability of the latter was more relevant in the context of data analysis, as the respondents gave detailed answers during data collection. By identifying the topics were highlighted those key problems which were closely related to the research problem.

\section{FINDINGS}

Data analysis of the quantitative research showed that $60 \%$ of respondents communicate easily with others, $7 \%$ had minor communication difficulties. 33\% of respondents have significant difficulties. The elderly explains those difficulties that they feel alone, think that people in the nursing home do not have common ground or have other attitudes (e.g. lack of mood, laziness) (Figure 1).

As a result of the research, it was revealed that the vast majority of respondents (93\%) do not have any occupation, do not perform any kind of work. This circumstance was explained not only by the lack of alternative occupation inside the institution, but also with the lack of desire. $7 \%$ of respondents have an occupation: they mostly take care a small garden in the area.

\section{Figure 1. Elderly Communication Skills}

\section{Communication}

$\square$ Yes $\quad$ With difficulty $\square$ No

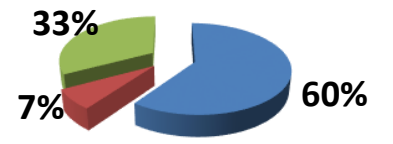

As a result of the research, it became clear that the main reason for the lack of occupation in the nursing home is that self-management is carried out by the staff of the institution: such as clothes washing, cleaning the area, cooking, shopping, etc. (Figure 2).

During the data collection for revealing "the favorite occupation" the responders had to offer their version of occupation. As a result of the research, the majority of respondents (20\%) believe that their daily life will be more meaningful and enjoyable if they often participate in any event. 
Figure 2. Work experience of elderly

\section{Occupation/education}

- Have Do not have $7 \%$
The least number of respondents who gave the most attention was walking (10\%), cleaning $(10 \%)$, gardening $(10 \%)$, table games $(8 \%)$ and sports (8\%) (Figure 3). The results of the research revealed that the respondents do not have meaningful occupation that they prefer. That is

why they show less activity, which leads to a deterioration of wellbeing.

The analysis of created questionnaire has shown that everyone's birthday celebrations, holidays are celebrated within the institution, also gatherings, walking's in the nearby area are organized. Sometimes excursions are organized. Often the events, small concerts and performances are organized by the students or volunteers (gardening, construction works).

Figure 3. Favorite occupation of elderly according to qualitative analysis.

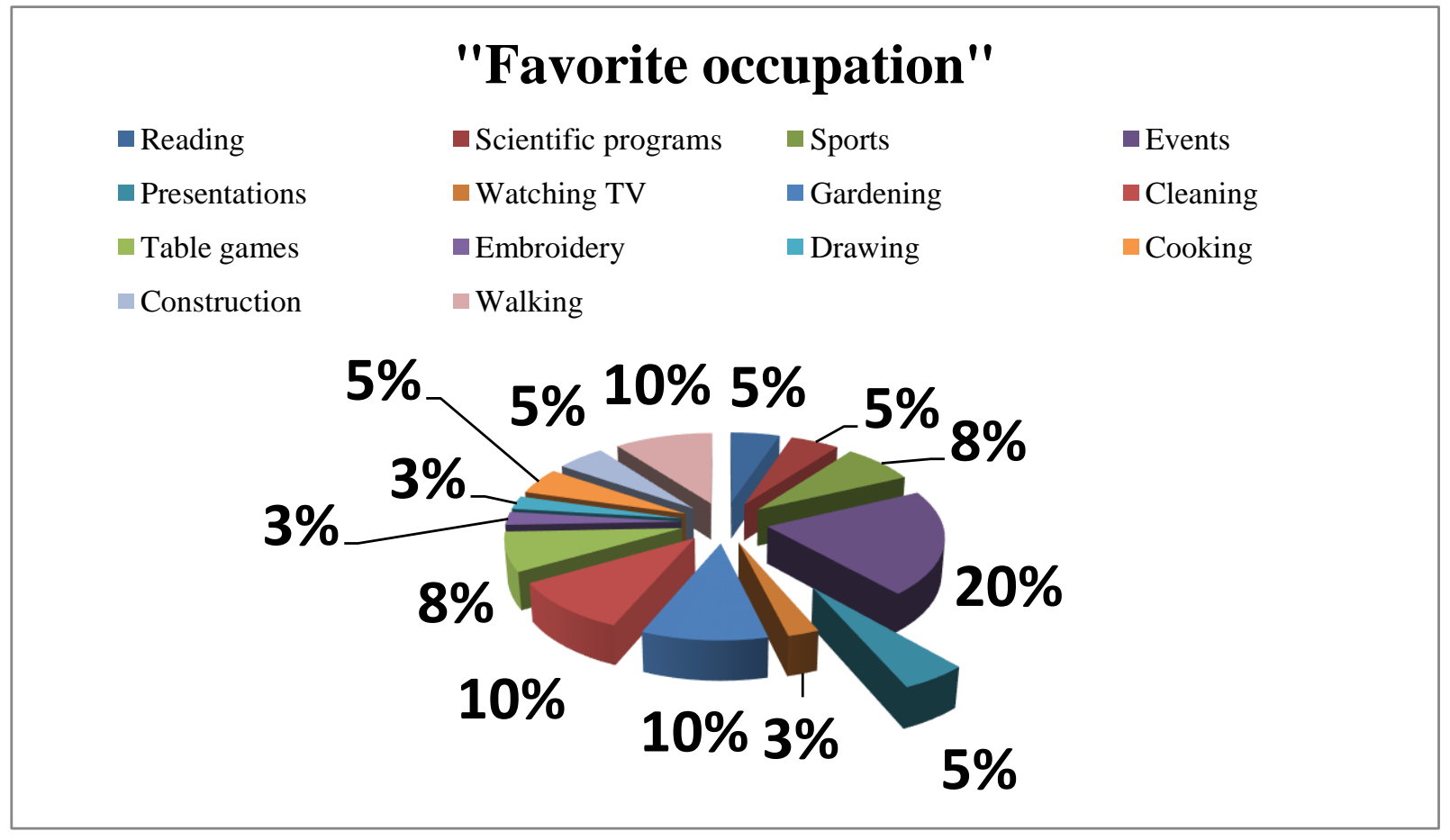

According to the research results, most elderly want to participate in performances (theatre - $34 \%$, movie theater $-17 \%$, opera $-17 \%$ ), and another group of respondents expressed a desire to participate in exhibitions ( $8 \%$ ) and go for a walk more (8\%). $8 \%$ of respondents reported that they 
were satisfied with the events that were carried out inside the institution, and another $8 \%$ does not want to participate in any event (Figure 4).

Figure 4. Desirable events of elderly people

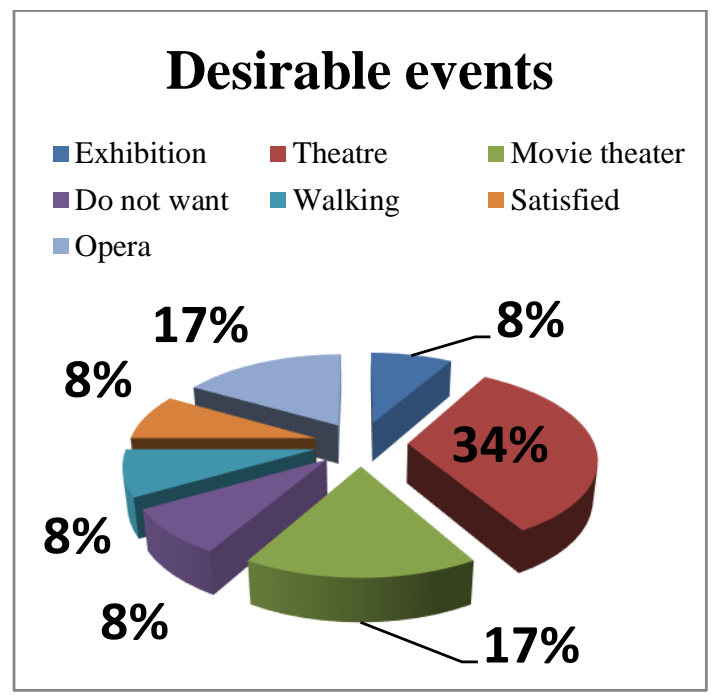

Figure 5. The reasons of not participation.

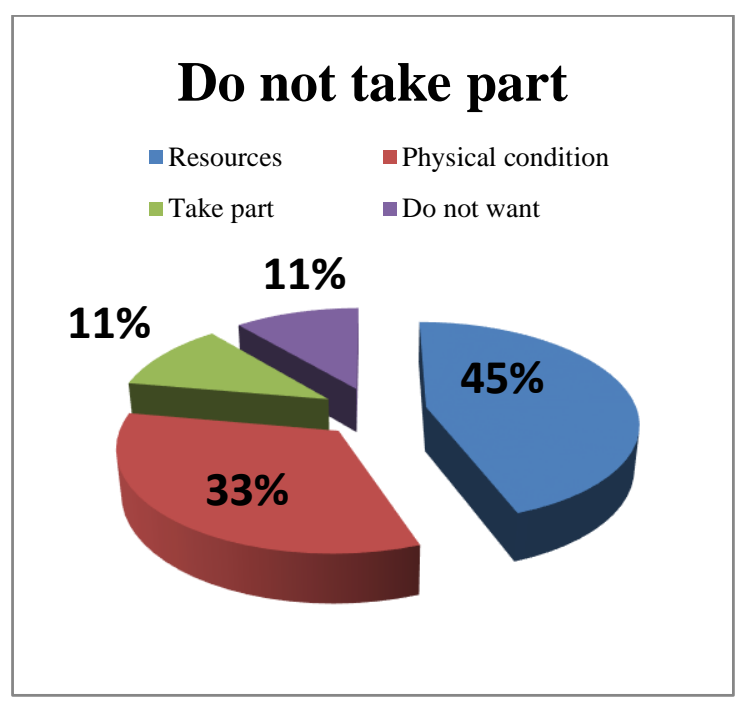

According to other questionnaire's data analysis, it turned out that $45 \%$ of respondents do not take part in the preferred event, because there are not enough financial and transport resources. $33 \%$ of respondents do not participate because of their physical condition. $11 \%$ of respondents take part in their favorite event and are satisfied, and 11\% do not want to participate in any event (Figure 5).

\section{DISCUSSION}

The aim of this research is to find out the importance of occupation in the lives of elderly people and identify the occupation therapy effect of their well-being. This research pursues the idea that aging is one of the most important stages of life that a person must live as efficiently as possible (Bonder \& Goodman, 2008), because it raises the quality of life, well-being, and wellbeing refers to the overall state of human life and reflects the level of human satisfaction with life (Searle, Mahon, Iso-Ahola, Sdrolias et al., 1998), which has been proven repeatedly during the research. At the same time, during the research, it was seen that on the quality of life of elderly can have a great impact such factors as psychological and social health, which play an important role in the ability to adapt to different situations of life. This fact was also pointed to by Johnson in his scientific article (Johnson \& Walker, 2016). One of the ideological problems is the ideology 
of Hanson and Jones, according to which the elderly not always need care. It should also be taken into account that aging should not be linked to illnesses or disabilities (Searle, Mahon, Iso-Ahola, Sdrolias et al., 1998). However, this became clear in the context of literature review, data collection and direct contact with elderly, that at present state social services in the Republic of Armenia are paying more attention to ensure minimum living conditions for the elderly, which significantly reduces the importance of meaningful occupation of elderly, while a study by Brown and Franklin in 1993 proves that one of the most important factors in ensuring quality of life is providing maximum independence in daily life (SWD, 2008), and this provides development of interpersonal relationships and communication skills (Chudnova, 2015; Wade, 2003).

The problem of research was formulated as follows: "What kind of rehabilitation effect will meaningful occupation provide on elderly' welfare".

The study by Jackson in 1998 proves the rehabilitation effect of occupational therapeutic interventions (Enderby \& Wade, 2001), as well as the purposefulness and meaningfulness of occupation (Trombly, 1995), but since there are no studies in the Republic of Armenia that would highlight the importance of occupation in the lives of elderly, we decided to conduct a research which aim is find out the importance of occupation in the lives of elderly people and identify the occupation therapy effect of their well-being in the Republic of Armenia. According to the results of this research, the importance of occupation is also proven in non-governmental boardingHouses in the Republic of Armenia, especially in "Narek" NGO.

The scarcity of meaningful occupation is also explained by the fact that there are no occupational therapists, gerontologists in the organizations dealing with the problems of elderly in the country, which does not allow to fully maintain the health of elderly and ensure a favorable environment for their livelihood, while the number of elderly people is gradually increasing and there is a need to provide them with additional social services (Mishra, 2003).

As a result of the above-mentioned research, it became clear that elderly is unable to participate and engage in their activities because they do not have enough health, physical and financial resources. During the data analysis, it became clear that $11 \%$ of respondents do not want to participate in any event.

In addition, the results of the research showed that elderly do not have a wide choice of occupation options. According to the data analysis results during the research revealed those desired events in which elderly want to participate, including cultural events, theater, exhibitions, 
cinema, opera. And only $8 \%$ of elderly respondents are satisfied with occupation opportunities within the institution.

\section{LIMITATION OF THE STUDY}

The aim of the study is to find out the importance of occupation in the lives of elderly people and identify the occupation therapy effect of their well-being, and, although this justified our expectations, the study has some limitations. The main limitation of research is the small number of the respondents.

One of the limitations of the research is that the survey was conducted only at "Narek" nongovernmental nursing home in the region of Kotayk. The results would be more extensive if the survey was conducted in all boarding-houses in the Republic of Armenia.

\section{IMPLICATIONS FOR PRACTICE AND FUTURE RESEARCH}

This research has revealed and once again highlighted the importance of meaningful occupation as an occupation therapy rehabilitation process in the lives of elderly. The sphere of occupation of elderly and gerontology is still open in Armenia. I think the study will help all the organizations dealing with the problem of elderly, including the state, organize events that will focus on the meaningful occupation of the elderly, which, in turn, will contribute to effective aging.

\section{CONCLUSION}

This study examines the occupation therapeutic effectiveness of occupation in the lives of elderly. The results of the study underline the importance of occupation and the impact on the quality of life of elderly people. As well as revealing the obstacles for participation and engagement in the occupation, restrictions on the variety of occupation, also desirable activities of elderly people. During the research also explored their capacity to engage in any occupation, as this is the way to:

- Improve the quality of life;

- Improve health;

- Mood enhancement;

- Increasing motivation to do any kind of occupation;

- Improve communication and social skills; 
- Increase physical and mental activity;

- Increase of work capacity.

\section{REFERENCE LIST}

1. American Occupational Therapy Association about Occupational Therapy (2019) doi// https://www.aota.org/Conference-Events/OTMonth/what-is-OT.aspx

2. American Occupational Therapy Association (2014) Occupational therapy practice framework: Domain and process, Third edition.

3. Bonder, B., \& Goodman, G. (2008) Occupational Therapy for physical dysfunction, "Preventing occupational dysfunctional secondary to aging" Capter 37, Lippincott Williams \& Wilkins.

4. Braun, V., \& Clarke, B. (2006) Using thematic analysis in psychology. Qualitative research in Psychology, 3, 77-101.

5. Brown, B., \& Frankel, B. (1993) Activity through the years: Leisure, leisure satisfaction, and life satisfaction. Sociology of Sport Journal, 10, 1-17.

6. Chevannes, M. (2002) Issues in educating health professionals to meet the diverse needs of patients and other service users from ethnic minority groups, Journal of Advanced Nursing, 39(3), 290-298.

7. Christiansen, C., Baum, M., \& Bass-Haugen, J. (2005) Occupational therapy: Performance, participation, and well-being. Thorofare, NJ: Slack.

8. Chudnova, O. (2015) Algoritm bazovogo analiza dannikh sociologicheskogo oprosa v programme MS Excel (Algorithm based analysis of sociological data in MS Excel), Samara.

9. Cumming, R. G., Thomas, M., Szonyi, G., Salkeld, G., O'Neill, E., Westbury, C., et al. (1999) Home visits by an occupational therapist for assessment and modification of environmental hazards: A randomized trial of falls prevention. Journal of the American Geriatrics Society, 47, 1397-1402.

10. Elderly population (2010) WHO Health situation in elderly population

11. Enderby, P., \& Wade, D. (2001). Community rehabilitation in the United Kingdom. Journal of Clinical Rehabilitation, 15, 577-581.

12. Graff, M. J. L., Vernooij-Dassen, M. J. M., Thijssen, M., Dekker, J., Hoefnagels, W. H. L., \& Rikkert, M. G. M. O. (2006) Community based occupational therapy for patients with 
dementia and their care givers: Randomised controlled trial. British Medical Journal, 333, 983-986.

13. Hansen, G., Ashby, S., \& Baug, I. (2015) Everyday products in the middle ages. Crafts, Consumption and the Indivudual in Northern Europe, Oxbow books.

14. Harutyunyan, Z. (2012) Ergotherapian vorpes tarecneri kyanqi voraki bardzracman mijoc (Occupational Therapy as a Mean of Improving the Quality of Life for the Elderly) "Mankavarjutyun" Gitamethodakan amsagir \# 1, 48-53.

15. HH Karavarutyan 18.09.2014 N39 ardzanagrayin voroshum (RA Government 18.09.2014 N 39 Protocol Decision) doi // http: //www.irtek.am/views/act.aspx? Aid = 77782

16. Johnson, M., Walker J. (2016) Spiritual diemnsions of aging, Cambridge University Press Chapter 34, p. 722.

17. Khrisanfova, E. (1999) Osnovi gerontologii (Gerontologies Basics), Moskva

18. Kielhofner, G. (2002) A model of human occupation: Theory and application, Fourth Edition, Lippincott Williams \& Wilkins.

19. Mayers, C. (1998) An evaluation of the use of the Mayers' Lifestyle Questionnaire. British Journal of Occupational Therapy, 61 (9), 393-98.

20. Mishra, S. (2003). Occupational therapy in community based rehabilitation. Indian Journal of Occupational Therapy, 35, 13-16.

21. Ng, S., Lo, A., Lee, G., Lam, M., Yeong, E., Koo, M., et al. (2006) Report of the outcomes of occupational therapy programs for elderly persons with mild cognitive impairment (MCI) in community elderly centers. Hong Kong Journal of Occupational Therapy, 16, 16-22.

22. Searle, M. S., Mahon, M. J., Iso-Ahola, S. E., Sdrolias, H. A., \& Dyck, J. V. (1998). Examining the long term effects of leisure education on a sense of independence and psychological well-being among the elderly. Journal of Leisure Research, 30, 331-340.

23. Social Welfare Department. (2008). Services for elders: In Social Welfare Department review (2005-2006 and 2006-2007). Hong Kong: Author, pp. 27-32.

24. Trombly, A., (1995) "Occupation: purposefulness and meaningfulness as therapeutic mechanism", American Journal of Occupational Therapy, Vol. 49, 960-972.

25. Wade, D. T. (2003). Community rehabilitation, or rehabilitation in the community. Disability and Rehabilitation, 25, 875-881. 
26. World Federation of Occupational Therapist. (n.d.). What is Occupational Therapy? Retrieved April 21, 2009, from http://www.wfot.org/ information.asp 